\title{
Article \\ Commutation Torque Reduction Strategy of Brushless DC Motor Based on Single-Input Dual-Output Cuk Converter
}

\author{
Xinmin $\mathrm{Li}^{1}{ }^{1}$, Jingxin Deng ${ }^{1}$, Wei Chen ${ }^{1}$, Lihong $\mathrm{Yu}^{2, *}$ and Xuefeng Jin ${ }^{1}$ \\ 1 School of Electrical Engineering, Tiangong University, Tianjin 300387, China; lixinmin@tju.edu.cn (X.L.); \\ dengjingxin@tiangong.edu.cn (J.D.); chenwei@tiangong.edu.cn (W.C.); jinxuefeng@tiangong.edu.cn (X.J.) \\ 2 College of Electronic Information and Automation, Civil Aviation University of China, Tianjin 300300, China \\ * Correspondence: lhyu@cauc.edu.cn
}

Citation: Li, X.; Deng, J.; Chen, W.; Yu, L.; Jin, X. Commutation Torque Reduction Strategy of Brushless DC Motor Based on Single-Input Dual-Output Cuk Converter. Machines 2022, 10, 117. https:// doi.org/10.3390/machines10020117

Academic Editor: Alejandro Gómez Yepes

Received: 25 December 2021

Accepted: 3 February 2022

Published: 6 February 2022

Publisher's Note: MDPI stays neutral with regard to jurisdictional claims in published maps and institutional affiliations.

Copyright: (C) 2022 by the authors. Licensee MDPI, Basel, Switzerland. This article is an open access article distributed under the terms and conditions of the Creative Commons Attribution (CC BY) license (https:// creativecommons.org/licenses/by/ $4.0 /)$.

\begin{abstract}
Based on the Single-Input Dual-Output (SIDO) Cuk converter, a novel commutation torque ripple suppression strategy is proposed for a brushless DC motor (BLDCM). Two voltage scalars are constructed, according to the operating principle of SIDO Cuk converter and BLDCM, and applied to the non-commutation and commutation periods, respectively, of BLDCM; the commutation torque ripple in the full speed range is effectively reduced, and this occurs without the need to switch the control strategy according to the speed range. The inverter in the proposed strategy is controlled by the pulse amplitude modulation (PAM) during both non-commutation and commutation periods, and the voltage spike damage caused by the inverter chopping to the motor can be minimized. In addition, the multiple outputs of the SIDO Cuk converter improve the utilization of the DC power for the BLDCM control system. The experimental results verify the effectiveness of the proposed strategy.
\end{abstract}

Keywords: brushless DC motor; commutation torque ripple; single-input dual-output cuk converter; pulse amplitude modulation

\section{Introduction}

Due to the advantages of small size, high power density, and simple structure, etc., brushless DC motors (BLDCM) are widely used in aerospace, household appliances, electric vehicles, and other fields [1-5]. However, during the operation of the motor, vibration and noise are generated due to the commutation torque ripple, which restricts the application of the motor in the high-performance field [6-8].

A series of studies have been conducted, by a wide range of scholars, to address the commutation torque ripple of BLDCM. In [9], the commutation torque ripple is analyzed and researched, and it is noted that the commutation torque ripple can be suppressed by maintaining a smooth non-commutation phase current. In [10], the PWM period during the commutation of the motor is divided into three parts, and, by adjusting the appropriate ratio of these three parts, the commutation torque ripple can be suppressed during each modulation period. In [11], a full-order Romberg observer is designed to estimate the opposite potential, optimize the reference phase current during motor operation, and use two-phase and three-phase conduction modes, switching control during commutation, in which the commutation torque ripple is reduced. A hybrid switching method is proposed in [12]; the motor is controlled by two-phase and three-phase conduction modes during the non-commutation and commutation periods, and the voltage compensation method is combined during the commutation period to suppress the commutation torque ripple.

The above strategies have a significant suppression effect on the commutation torque ripple, but the control mode needs to be changed frequently. In [13], a finite set model prediction strategy for commutation torque ripple suppression is proposed. A discrete time non-commutation current prediction model is established during the commutation period, and the optimal switching state for the next control cycle is judged according to the value 
function. In [14], a main and auxiliary vector table is designed, adopted, and a unified vector selection strategy is applied to the non-commutation and commutation periods of the motor; the commutation torque ripple is suppressed by the joint action of the main and auxiliary vectors in each control cycle.

During the operation of the motor, the control strategy does not need to switch between the above two strategies. However, when the motor is running in the high speed range, it is limited by the DC side voltage of the inverter and cannot effectively suppress the commutation torque ripple in the full speed range.

In this regard, a control strategy, adding a DC-DC converter at the front end of the inverter, has been proposed to provide a higher voltage to the BLDCM by adjusting the DC bus voltage during commutation, thereby solving the commutation torque in the full speed range [15]. In [16], the SEPIC converter is used to increase the DC link voltage during the commutation period, and the switch selection circuit is used to select the DC power supply in order to provide energy for the motor during the non-commutation period. In [17], the commutation torque ripple can be reduced by adjusting the Z-source inverter through vector and the effective vector duty cycle. This strategy can also use a DC power supply which is lower than the rated voltage of the motor to improve the utilization rate of the power supply voltage. In [18], the inverter input voltage is changed by two working modes of the Cuk converter; the boost mode is used to keep the non-commutated phase current stable during the commutation period. The PAM method is applied during the normal conduction period of the inverter in order to reduce the voltage spike damage caused by the PWM to the motor.

A single-input dual-output (SIDO) Cuk converter is proposed in [17]. Compared with the traditional two independent Cuk converters, this converter has excellent interleaved control, and it greatly reduces the number of components. To control the power switch in the SIDO Cuk converter, two different voltage values can be output at the same time in a modulation period, and one output voltage is always greater than the other output, which provides a new idea for suppressing commutation torque ripple.

A novel BLDCM commutation torque ripple suppression strategy, based on the SIDO Cuk converter, is proposed in this paper. A unified control method is adopted by this strategy in order to suppress the commutation torque ripple in the full speed range. The lower and higher voltage outputs of the SIDO Cuk converter are used to provide energy to the motor during the non-commutation and commutation periods, respectively. The inverter is controlled using only the PAM method to minimize voltage spike damage to the motor. For industrial applications with lower DC power supply voltage, the power supply voltage utilization rate can be improved by using the two output voltages of the SIDO Cuk converter.

\section{The BLDCM Operation Principle Driven by the SIDO Cuk Converter}

\subsection{The Working Principle of the SIDO Cuk Converter}

The proposed SIDO Cuk converter-driven BLDCM system is shown in Figure 1, and this system consists of the SIDO Cuk converter (in the red dashed box), selection circuit (in the blue dashed box), the inverter, and the BLDCM.

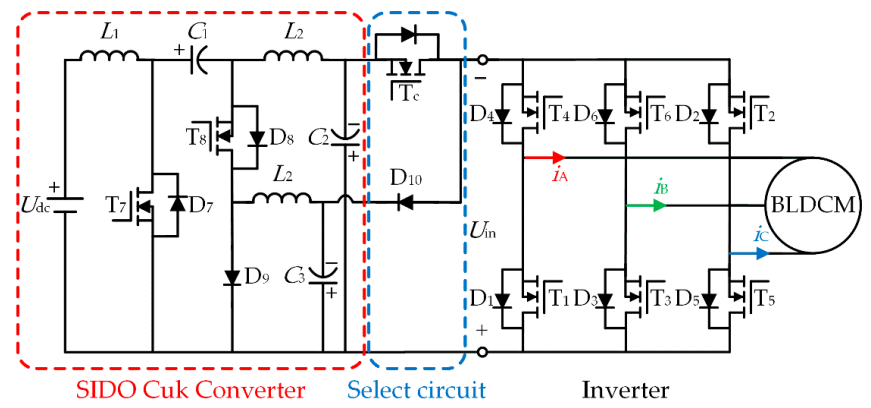

Figure 1. The BLDCM system driven by the SIDO Cuk converter. 
The SIDO Cuk converter is composed of power switches $\left(\mathrm{T}_{7}, \mathrm{~T}_{8}\right)$, diode $\left(\mathrm{D}_{9}\right)$, inductors $\left(L_{1-} L_{3}\right)$, and capacitors $\left(C_{1-} C_{3}\right)$. The selection circuit is composed of a power switch $\left(\mathrm{T}_{\mathrm{c}}\right)$ and a diode $\left(\mathrm{D}_{10}\right) . \mathrm{T}_{1}-\mathrm{T}_{6}$ are the power switches of the inverter, $\mathrm{D}_{1}-\mathrm{D}_{6}$ are the anti-parallel diodes of the corresponding power switches, $U_{\mathrm{dc}}$ is the DC supply voltage, $U_{\mathrm{in}}$ is the input voltage of the inverter, and $i_{\mathrm{A}}, i_{\mathrm{B}}$, and $i_{\mathrm{C}}$ are the phase currents.

According to the switching states of the two power switches in the SIDO Cuk converter, within a control period, the output of the SIDO Cuk converter is composed of three intervals, and the corresponding equivalent circuits are shown in Figure 2.

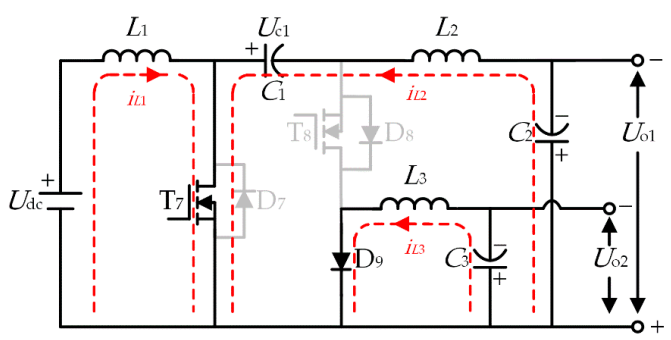

(a)

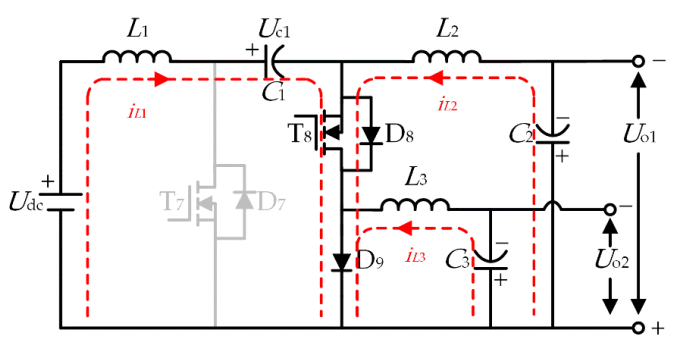

(b)

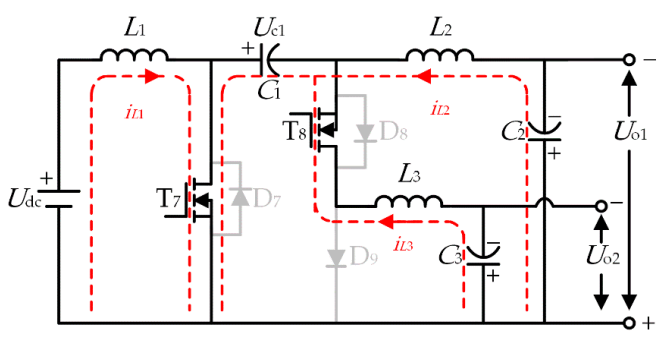

(c)

Figure 2. The equivalent circuits of the SIDO Cuk converter operation: (a) $T_{7}$ on, $T_{8}$ off; (b) $T_{7}$ off, $T_{8}$ on; and (c) $\mathrm{T}_{7}$ on, $\mathrm{T}_{8}$ on.

\subsection{1. $\mathrm{T}_{7}$ on and $\mathrm{T}_{8}$ off}

As shown in Figure $2 \mathrm{a}, \mathrm{D}_{9}$ turns on positively. During this interval, $L_{1}$ is charged by $U_{\mathrm{dc}}, L_{2}$ is charged by $U_{\mathrm{c} 1}-U_{\mathrm{o} 1}, L_{3}$ is discharged through $U_{\mathrm{o} 2}$, and $C_{1}$ is discharged through current $-i_{\mathrm{L} 2}$. At this time, the voltage across $L_{1}-L_{3}$ and the current value of $C_{1}$ are expressed as

$$
\left\{\begin{array}{l}
u_{L 1}=U_{\mathrm{dc}} \\
u_{L 2}=U_{C 1}-U_{\mathrm{o} 1} \\
u_{L 3}=U_{\mathrm{o} 2} \\
i_{C 1}=-i_{L 2}
\end{array}\right.
$$


where $u_{L 1}-u_{L 3}$ are represented as the voltages at the terminals of $L_{1-} L_{3}, U_{C 1}$ and $i_{C 1}$ are the voltage value and the value of the current flowing through $C_{1} \cdot U_{\mathrm{o} 1}$ and $U_{\mathrm{o} 2}$ are expressed as the output voltage of the two output terminals of the SIDO Cuk converter.

\subsection{2. $\mathrm{T}_{7}$ off and $\mathrm{T}_{8}$ on}

As shown in Figure 2b, during this interval, the current $i_{\mathrm{L} 1}+i_{\mathrm{L} 2}$ flows from the antiparallel diode $\mathrm{D}_{8}$ of $\mathrm{T}_{8}$. If $\mathrm{T}_{8}$ is turned on at this time, it will act as a synchronous rectifier switch. $L_{1}, L_{2}$, and $L_{3}$ are discharged through $-U_{\mathrm{c} 1}+U_{\mathrm{dc}},-U_{\mathrm{o} 1}$, and $-U_{\mathrm{o} 2} . C_{1}$ is charged by $i_{\mathrm{L} 1}$. At this time, the voltage across $L_{1}-L_{3}$ and the current value of $C_{1}$ are given by

$$
\left\{\begin{array}{l}
u_{L 1}=U_{\mathrm{dc}}-U_{C 1} \\
u_{L 2}=-U_{\mathrm{o} 1} \\
u_{L 3}=-U_{\mathrm{o} 2} \\
i_{C 1}=i_{L 1}
\end{array}\right.
$$

\subsection{3. $\mathrm{T}_{7}$ on, $\mathrm{T}_{8}$ on}

As shown in Figure $2 c, D_{9}$ is reversely cut off. During this interval, $L_{1}, L_{2}$, and $L_{3}$ are charged through $U_{\mathrm{dc}}, U_{\mathrm{c} 1}-U_{\mathrm{o} 1}$, and $U_{\mathrm{c} 1}-U_{\mathrm{o} 2}$. $C_{1}$ is discharged by the current $-i_{\mathrm{L} 2}-i_{\mathrm{L} 3}$. At this time, the voltage across $L_{1-} L_{3}$ and the current value of $C_{1}$ are expressed as

$$
\left\{\begin{array}{l}
u_{L 1}=U_{\mathrm{dc}} \\
u_{L 2}=U_{C 1}-U_{\mathrm{o} 1} \\
u_{L 3}=U_{C 1}-U_{\mathrm{o} 2} \\
i_{C 1}=-i_{L 2}-i_{L 3}
\end{array}\right.
$$

According to the flux balance, the average inductor voltage of $L_{1}-L_{3}$ is zero in a control period. According to the above formula (1) to (3), the relationship between the output voltage $U_{\mathrm{o} 1}$ and $U_{\mathrm{o} 2}$, the capacitor voltage $U_{\mathrm{C} 1}$, and the DC power supply voltage $U_{\mathrm{dc}}$ can be derived as

$$
\left\{\begin{array}{l}
U_{\mathrm{C} 1}=\frac{1}{1-d_{7}} U_{\mathrm{dc}} \\
U_{\mathrm{o} 1}=\frac{d_{7}}{1-d_{7}} U_{\mathrm{dc}} \\
U_{\mathrm{o} 2}=\frac{d_{7}+d_{8}-1}{1-d_{7}} U_{\mathrm{dc}}
\end{array}\right.
$$

where $d_{7}$ and $d_{8}$ are the duty of power switches $\mathrm{T}_{7}$ and $\mathrm{T}_{8}$, it can be observed that $U_{\mathrm{o} 1}$ is controlled by $d_{7}$, and $U_{02}$ is controlled by $d_{8}$, and the relationship between $d_{7}$ and $d_{8}$ is as follows

$$
\left\{\begin{array}{l}
0<d_{7}<1 \\
0<d_{8}<1 \\
d_{7}+d_{8}>1
\end{array}\right.
$$

It can be observed that the two output voltages are regulated by two independent control variables, and the output $U_{\mathrm{o} 1}$ is the same as in the conventional Cuk converter, and it always contains $U_{\mathrm{o} 1}>U_{\mathrm{o} 2}[19]$.

\subsection{The BLDCM Operation Principle under ON-PWM Modulation}

The BLDCM usually operates in two-phase conduction mode. There are six commutation cycles in a $360^{\circ}$ electrical cycle, which means that two-phase windings are in conduction during each commutation cycle, and the other phase winding in a suspended state.

The ideal back electromotive forces (EMFs), ideal phase current, and ON-PWM modulation method of the BLDCM is shown in Figure 3, where $\theta$ is the electrical angle. There are six commutation cycles in a $360^{\circ}$ electrical cycle. Observe the B phase as an example; when the $B$ phase is the positive or negative conducting phase, the power switch $T_{3}$ or $T_{6}$ conducts in the first $60^{\circ}$ electrical angles and chops in the last $60^{\circ}$. When the $B$ phase is the overhanging phase, both $\mathrm{T}_{3}$ and $\mathrm{T}_{6}$ are turned off. 


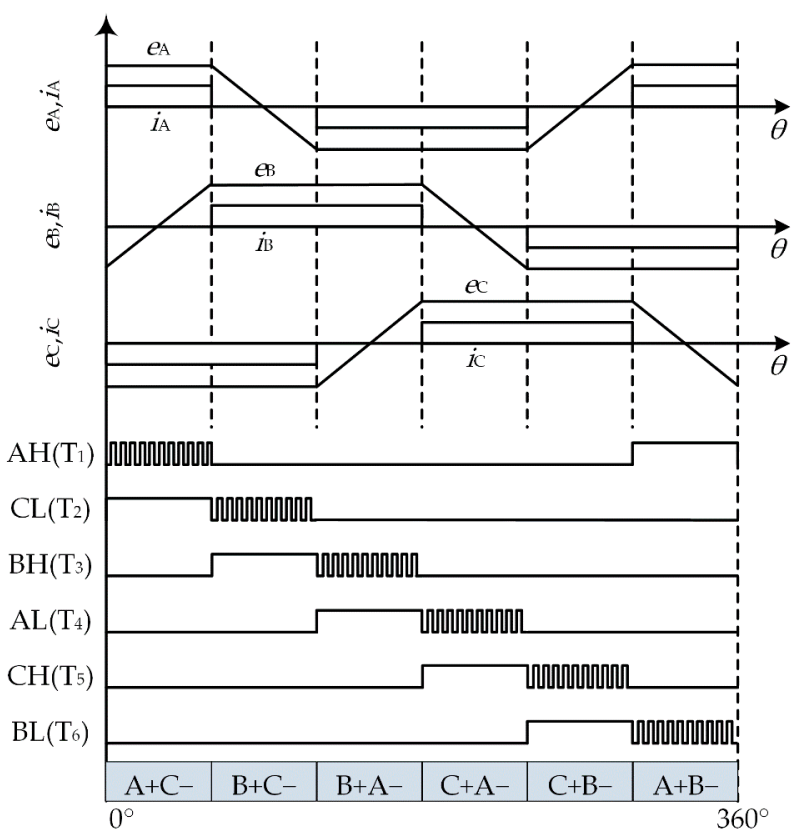

Figure 3. Ideal back EMFs, ideal phase current, and ON-PWM modulation method of the BLDCM.

Assuming that the magnetic circuit of the motor is not saturated, ignoring the influence of the voltage drop of the power switch and its own structure, the voltage equation of the three-phase winding terminal of the BLDCM can be expressed as follows:

$$
\left\{\begin{array}{l}
u_{\mathrm{A}}=R i_{\mathrm{A}}+L \frac{\mathrm{d} i_{\mathrm{A}}}{\mathrm{d} t}+e_{\mathrm{A}}+u_{\mathrm{N}} \\
u_{\mathrm{B}}=R i_{\mathrm{B}}+L \frac{\mathrm{d} i_{\mathrm{B}}}{\mathrm{d} t}+e_{\mathrm{B}}+u_{\mathrm{N}} \\
u_{\mathrm{C}}=R i_{\mathrm{C}}+L \frac{\mathrm{d} i_{\mathrm{C}}}{\mathrm{d} t}+e_{\mathrm{C}}+u_{\mathrm{N}}
\end{array}\right.
$$

where $u_{\mathrm{A}}, u_{\mathrm{B}}$, and $u_{\mathrm{C}}$ are the phase voltages of the three-phase windings of the motor, $i_{\mathrm{A}}, i_{\mathrm{B}}$, and $i_{\mathrm{C}}$ are the phase currents, $e_{\mathrm{A}}, e_{\mathrm{B}}$, and $e_{\mathrm{C}}$ are the phase back EMFs, and $u_{\mathrm{N}}$ is the neutral point voltage of the motor.

Observe the $\mathrm{B}+\mathrm{A}-$ conduction period as an example; the $\mathrm{B}$ phase is the positive conducting phase, the A phase is the negative conducting phase, and the $\mathrm{C}$ phase is an inactive phase, as shown in Figure 3. When the DC supply voltage $U_{\mathrm{dc}}$ is constant, the input voltage of the inverter satisfies $U_{\mathrm{in}}=U_{\mathrm{dc}}$, and the speed regulation of the motor is satisfied by the PWM method of the inverter. Through the first and second equations of Equation (6), the line voltage between phases B and A during the non-commutation period can be obtained as

$$
u_{\mathrm{BA}}=u_{\mathrm{B}}-u_{\mathrm{A}}=-2 R i_{\mathrm{A}}-2 L \frac{\mathrm{d} i_{\mathrm{A}}}{\mathrm{d} t}+2 E
$$

During the whole modulation period, the phase current of the negative conduction phase A hardly changes, and the average value of the line voltage $u_{\mathrm{BA}}$ of the two phases $\mathrm{B}$ and A can be obtained as

$$
U_{\mathrm{BA}}=\bar{u}_{\mathrm{BA}}=-2 R i_{\mathrm{A}}+2 E
$$

\subsection{The BLDCM Commutation Principle}

Observe the $\mathrm{B}+\mathrm{A}-\rightarrow \mathrm{C}+\mathrm{A}-$ commutation period as an example for analysis. During the commutation period, $T_{3}$ is turned off, $T_{5}$ is turned on, and $T_{4}$ is modulated by PWM. Due to the presence of inductance in the motor windings, the commutation process cannot be completed instantaneously, and freewheeling through $\mathrm{D}_{6}$ is required, as shown 
in Figure 4. Ignoring the conduction voltage drop of the power switch and the freewheeling diode, the voltage equation of the three-phase winding terminal is obtained as

$$
\left\{\begin{array}{l}
\left(1-d_{\mathrm{com}}\right) U_{\mathrm{in}}=R i_{\mathrm{A}}+L \frac{\mathrm{d} i_{\mathrm{A}}}{\mathrm{d} t}+e_{\mathrm{A}}+u_{\mathrm{N}} \\
0=R i_{\mathrm{B}}+L \frac{\mathrm{d} i_{\mathrm{B}}}{\mathrm{d} t}+e_{\mathrm{B}}+u_{\mathrm{N}} \\
U_{\mathrm{in}}=R i_{\mathrm{C}}+L \frac{\mathrm{d} i_{\mathrm{C}}}{\mathrm{d} t}+e_{\mathrm{C}}+u_{\mathrm{N}}
\end{array}\right.
$$

where $d_{\text {com }}$ is the duty cycle of power switch $\mathrm{T}_{4}$ during the commutation period. Normally, the motor commutation time is short, and it can be assumed that the opposite electric potential remains constant during the commutation, i.e. $-e_{\mathrm{A}}=e_{\mathrm{B}}=e_{\mathrm{C}}=E$. According to Kirchhoff's law, the three phase currents satisfy $i_{\mathrm{A}}+i_{\mathrm{B}}+i_{\mathrm{C}}=0$. The neutral point voltage is obtained as

$$
u_{\mathrm{N}}=\frac{\left(2-d_{\mathrm{com}}\right) U_{\text {in }}-E}{3}
$$

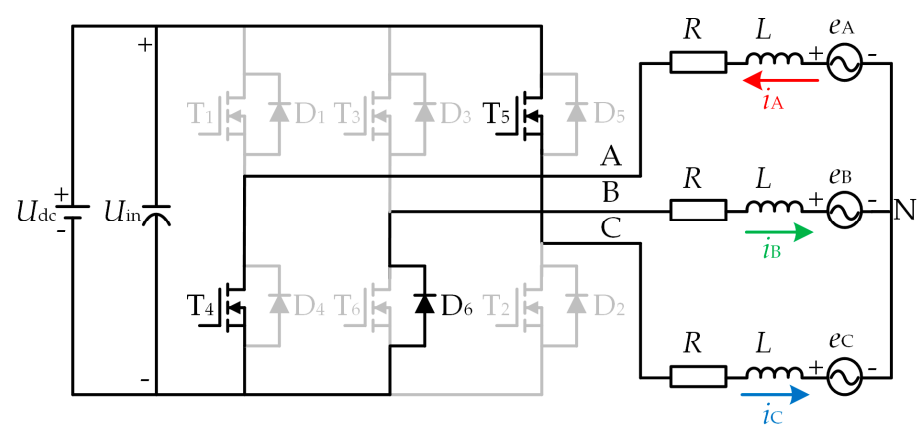

Figure 4. The circuit in the commutation from $B+A-$ to $C+A-$.

Substituting (10) to (9), the non-commutation current change rate is

$$
\frac{\mathrm{d} i_{\mathrm{A}}}{\mathrm{d} t}=\frac{\left(1-2 d_{\mathrm{com}}\right) U_{\mathrm{in}}+4 E-3 R i_{\mathrm{A}}}{3 L}
$$

Since the current exists in all three windings of the motor during the commutation, the equation pertaining to the electromagnetic torque of the brushless DC motor is

$$
T_{\mathrm{e}}=\frac{e_{\mathrm{A}} i_{\mathrm{A}}+e_{\mathrm{B}} i_{\mathrm{B}}+e_{\mathrm{C}} i_{\mathrm{C}}}{\omega_{\mathrm{m}}}
$$

where $\omega_{\mathrm{m}}$ is the mechanical angular velocity of the brushless DC motor.

According to the opposite potential and phase current during the commutation, the electromagnetic torque during the commutation can be obtained as

$$
T_{\mathrm{ec}}=-\frac{2 E i_{\mathrm{A}}}{\omega_{\mathrm{m}}}=\frac{2 E I}{\omega_{\mathrm{m}}}
$$

where $I$ is the steady-state value of the phase current.

From Equation (13), it can be observed that the electromagnetic torque during the commutation period $\left(T_{\mathrm{ec}}\right)$ is proportional to the non-commutation phase current during the commutation period. In other words, keeping the non-commutation phase current stable can suppress the ripple of commutation torque. From the structure of Equation (11), the rate of change of $i_{\mathrm{A}}$ is zero in order to make the non-commutation phase current stable during the actual operation of the motor, which can be derived

$$
d_{\mathrm{com}}=0.5+\frac{4 E-3 R i_{\mathrm{A}}}{2 U_{\mathrm{in}}}=0.5+\frac{4 E+3 R I}{2 U_{\mathrm{in}}}
$$


According to Equation (14), when the DC supply voltage $U_{\mathrm{dc}}$ is constant, the duty cycle of commutation under ON-PWM modulation method needs to satisfy $0 \leq d_{\text {com }} \leq 1$. It can be observed that the rate of change of the non-commutated phase current during commutation depends on the relationship between $U_{\text {in }}$ and $4 E+3 R I$. If the input voltage of the inverter $U_{\text {in }} \geq 4 E+3 R I$ is maintained during the commutation, the commutation torque ripple can be effectively suppressed.

\section{The Voltage Scalar Construction at the Output of the SIDO Cuk Converter Regulator Circuit}

This section will combine the SIDO Cuk converter, described in the previous section, and the BLDCM operation principle in order to design the voltage scalar that enables the motor to run smoothly.

The voltage scalars $V_{\mathrm{m} 1}$ and $V_{\mathrm{m} 2}$ are constructed for the on-state of the power switch $\mathrm{T}_{\mathrm{c}}$ and diode $\mathrm{D}_{10}$ in the selection circuit in Figure 5. The equivalent circuits for the different voltage scalars are shown in Figure 5.

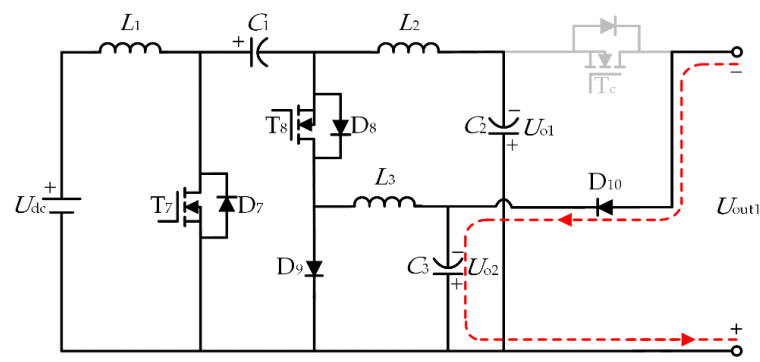

(a)

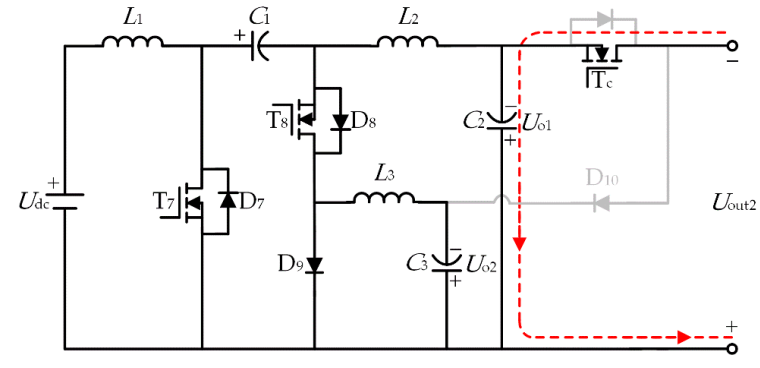

(b)

Figure 5. The equivalent circuits under different voltage scalars: (a) $V_{\mathrm{m} 1}$; and (b) $V_{\mathrm{m} 2}$.

$V_{\mathrm{m} 1}$ : As shown in Figure $5 \mathrm{a}, \mathrm{T}_{\mathrm{c}}$ is turned on, $\mathrm{D}_{10}$ is reversely cut off, the output of the SIDO Cuk converter $C_{3}$ is used as the overall output of the voltage regulating circuit, and, at this time, $C_{3}$ is used alone for the motor power supply; the inverter input voltage to meet $U_{\text {in }}=U_{\text {out } 1}=U_{\mathrm{o} 2}$.

$V_{\mathrm{m} 2}$ : As shown in Figure $5 \mathrm{~b}, \mathrm{~T}_{\mathrm{c}}$ is turned off, $\mathrm{D}_{10}$ is turned on, the output of the SIDO Cuk converter $C_{2}$ is used as the overall output of the voltage regulating circuit, and, at this time, $C_{2}$ is used alone for the motor power supply; the inverter input voltage to meet $U_{\text {in }}=U_{\text {out } 2}=U_{\mathrm{o} 1}$.

According to Kirchhoff's law, the input voltage of the inverter with different voltage scalars is expressed as

$$
U_{\text {in }}= \begin{cases}U_{\text {out } 1}=U_{\mathrm{o} 2,} & V_{\mathrm{m} 1} \\ U_{\text {out } 2}=U_{\mathrm{o} 1,} & V_{\mathrm{m} 2}\end{cases}
$$

Through the above analysis, the inverter will select different input voltage values when the power switch $T_{c}$ is in different switching states, especially when $T_{C}$ is turned on, $U_{\mathrm{o} 1}>U_{\mathrm{dc}}$ is always satisfied by $V_{\mathrm{m} 2}$, which can maintain the input voltage of the inverter 
$U_{\text {in }}=4 E+3 R I$ during the commutation period of the motor running in the high-speed range, and thus suppress the commutation torque ripple.

\section{The Proposed Method of Suppressing the Commutation Torque Ripple}

The energy of the BLDCM operation during the non-commutation and commutation periods is provided by two different output voltages of the SIDO Cuk converter in order to reduce the commutation torque ripple. In this paper, the proposed commutation torque ripple reduction strategy shown in Figure 6 is designed. The control unit includes the voltage scalar selection circuit, the non-commutation (NC) phase current stable strategy, and the detection module. The voltage scalar selection circuit is designed to switch the different output voltages of the SIDO Cuk converter. A higher output voltage is selected during the commutation period in order to increase the input voltage of the inverter. During the non-commutation period, the lower voltage regulation of the SIDO Cuk converter is realized through the speed and current PI controller in order to meet the speed regulation requirements of the motor. The reference speed $n^{*}$ is given by the host computer, and the output of the speed PI controller is the reference current $i^{*}$. The NC phase current stable strategy is adopted in order to realize higher voltage regulation of the SIDO Cuk converter, maintain the stability of the $\mathrm{NC}$ phase current, and suppress the commutation torque ripple. The signals $\left(i_{\mathrm{A}}, i_{\mathrm{B}}, i_{\mathrm{C}}\right.$ and $\left.H_{\mathrm{A}}, H_{\mathrm{B}}, H_{\mathrm{C}}\right)$ of the sensor are collected by the detection module in order to judge the start and end signals of the commutation period and detect the NC phase current value.

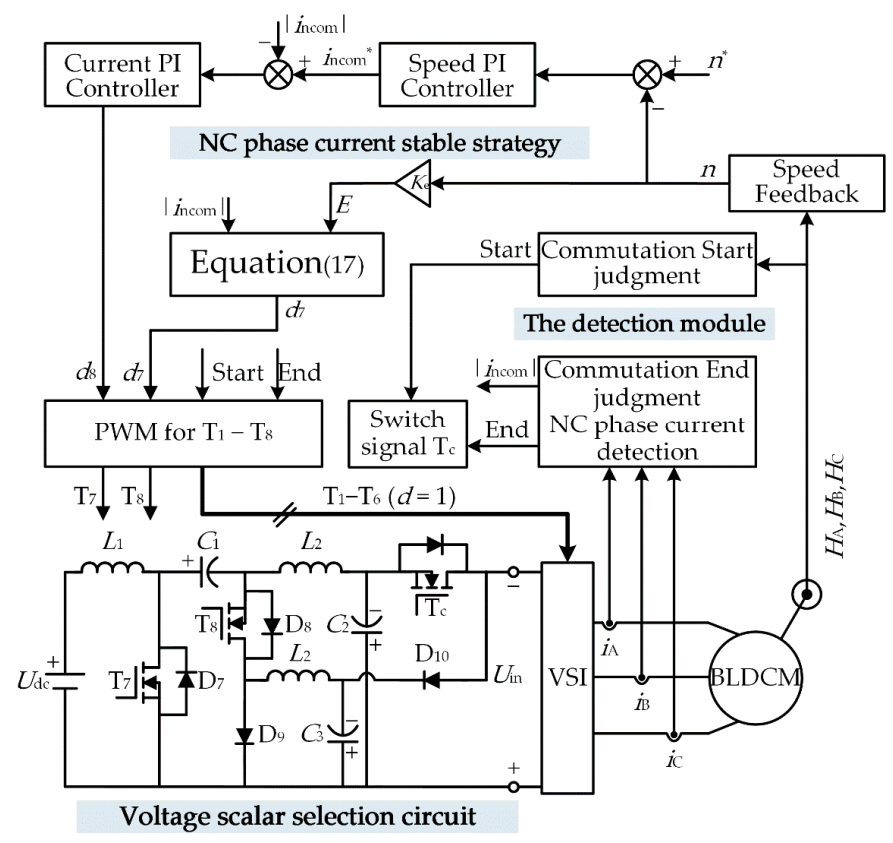

Figure 6. The proposed commutation torque ripple reduction strategy.

The speed adjustment of the motor can be achieved by chopping the inverter or controlling the PAM method. Compared with the traditional ON-PWM modulation method, the proposed method uses the PAM method to control the inverter during both the commutation period and the non-commutation period. It can minimize the voltage spikes and current ripples generated by PWM modulation.

\subsection{The Control Strategy during the Commutation Period}

During the commutation process, due to the existence of the winding inductance, the phase current cannot be changed abruptly, and, as a result, this stage is called the commutation period of the BLDCM. In order to suppress the commutation torque ripple, it 
can be observed from Equation (14) that $U_{\text {in }} \geq 4 E+3 R I$ is satisfied during the commutation period, and the non-commutation current is stabilized.

In the control strategy proposed in this paper, the PAM method is used to control the inverter. When the transition edge (rising edge, falling edge) of the Hall signal $\left(H_{\mathrm{A}}, H_{\mathrm{B}}\right.$, $\left.H_{C}\right)$ is detected, the commutation process is started. In order to inhibit the commutation torque ripple, $\mathrm{T}_{\mathrm{c}}$ is turned on and the voltage scalar $V_{\mathrm{m} 2}$ is selected as the inverter input voltage, as shown in Figure 5b, and, at this time, the duty cycle during commutation in Equation (14) satisfies $d_{\mathrm{com}}=1$; it can be observed that $V_{\mathrm{m} 2}$ is satisfied

$$
U_{\mathrm{out} 2}=U_{\mathrm{o} 1}=4 E+3 R I
$$

Since the output $U_{\mathrm{o} 1}$ of the SIDO Cuk converter is the same as that of the traditional Cuk converter, and the output is controlled by the power switch $\mathrm{T}_{7}$, substituting (16) into (4) the second equation, the duty cycle of $\mathrm{T}_{7}$ can be obtained as

$$
d_{7}=\frac{4 E+3 R I}{U_{\mathrm{dc}}+4 E+3 R I}
$$

When it is detected that the outgoing current becomes zero during the commutation process, the commutation process is ended, the $T_{c}$ is turned off, and the control strategy during the non-commutation period is entered. The corresponding relationship between back EMFs, phase current, and Hall signal is shown in Figure 7 . The Hall signal's $\left(H_{\mathrm{A}}, H_{\mathrm{B}}\right.$, $H_{\mathrm{C}}$ ) and the commutation signal's (Com) high levels are drawn by bold lines. As shown in Figure $7 \mathrm{a}$, according to the transition edge (rising edge, falling edge) of the Hall signal $\left(\mathrm{H}_{\mathrm{A}}\right.$, $\left.H_{\mathrm{B}}, H_{\mathrm{C}}\right)$, a $360^{\circ}$ electrical cycle can be divided into six commutation cycles. Observing the $\mathrm{B}+\mathrm{C}-$ to $\mathrm{B}+\mathrm{A}-$ commutation process of the Hall signal $\left(H_{\mathrm{A}}\right)$ transition as an example, the detailed commutation process is shown in Figure $7 \mathrm{~b}$. At time $t_{0}$, the transition edge signal (falling edge) of $H_{\mathrm{A}}$ is detected, and the commutation process is started; during the period from $t_{0}$ to $t_{1}, i_{\mathrm{A}}$ increases from 0 to $-I$, and $i_{\mathrm{C}}$ decreases from $-I$ to 0 ; at time $t_{1}$, it is detected that $i_{C}$ becomes 0 , and the commutation process is ended.

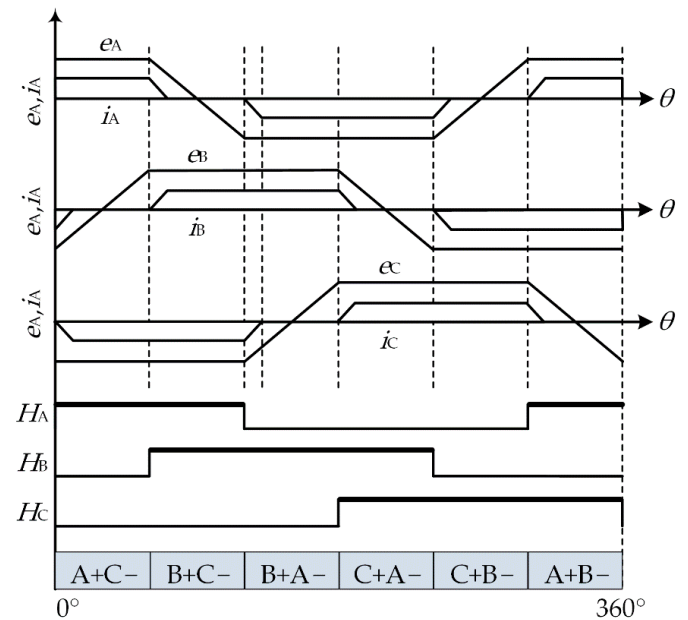

(a)

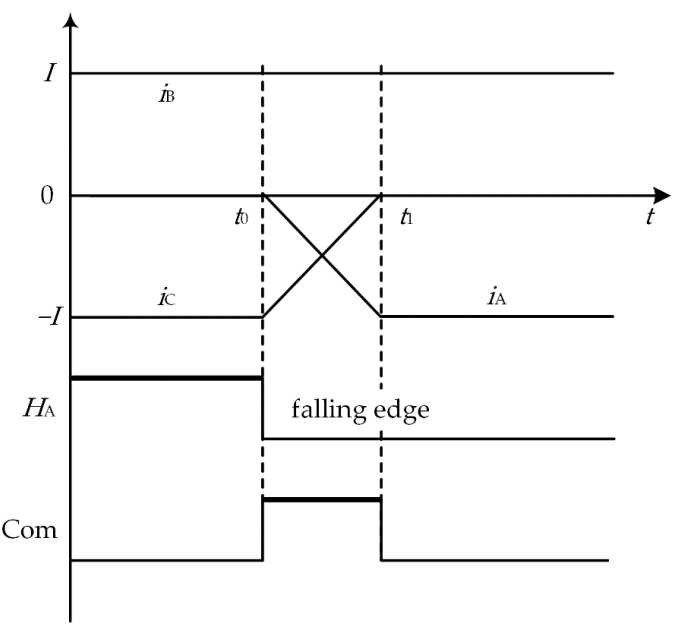

(b)

Figure 7. The corresponding relationship between back EMFs, phase current, and Hall signal: (a) The corresponding relationship in $360^{\circ}$ electrical cycle; and (b) The commutation process of $\mathrm{B}+\mathrm{C}-$ to $\mathrm{B}+\mathrm{A}-$.

\subsection{The Control Strategy during the Non-Commutation Period}

During the non-commutation period, in order to prevent the inverter control mode from being changed, the PAM mode control is still adopted. For the speed regulation performance of the motor to be satisfied, as shown in Figure $5 \mathrm{a}, \mathrm{T}_{\mathrm{C}}$ is turned off, and the 
voltage scalar $V_{\mathrm{m} 1}$ is selected as the inverter input voltage. It is known from Equation (8) that $U_{\mathrm{in}}=2 E+2 R I$, that is, $V_{\mathrm{m} 1}$ is expressed as

$$
U_{\text {out } 1}=U_{\mathrm{o} 2}=2 E+2 R I
$$

Since the output $U_{\mathrm{o} 2}$ of the SIDO Cuk converter is controlled by the power switches $\mathrm{T}_{7}$ and $\mathrm{T}_{8}$, substituting (18), (17) into (4) the third formula, the duty ratio of $\mathrm{T}_{8}$ can be obtained as

$$
d_{8}=\frac{U_{\mathrm{dc}}+2 E+2 R I}{U_{\mathrm{dc}}+4 E+3 R I}
$$

The modulation method of the proposed commutation torque ripple suppression strategy is shown in Figure 8.

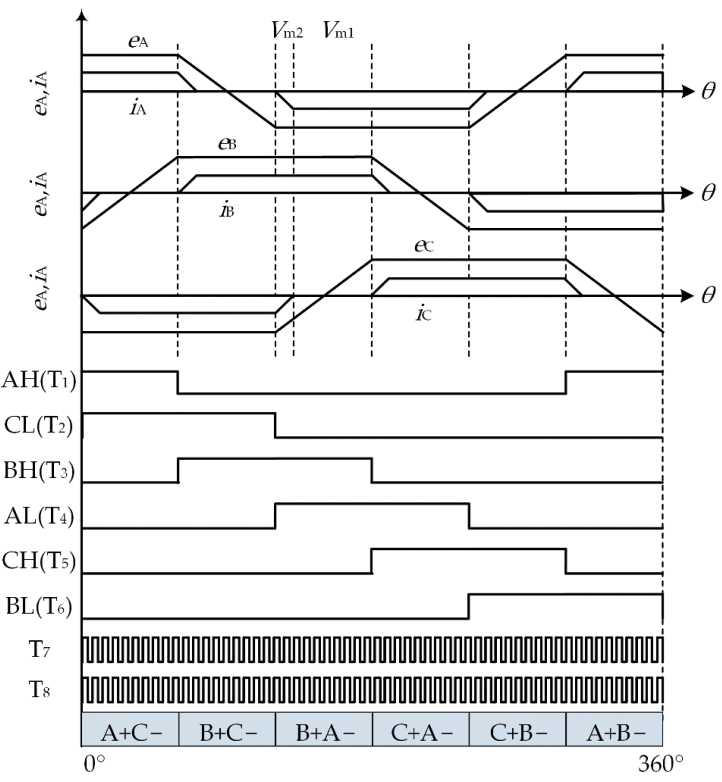

Figure 8. The modulation method of the proposed commutation torque ripple suppression strategy.

When the motor is running during the non-commutation period, $\mathrm{T}_{\mathrm{c}}$ is turned off. The voltage scalar $V_{\mathrm{m} 1}$ is selected as the inverter input voltage, and the power switch $\mathrm{T}_{8}$ in the SIDO Cuk converter is adjusted by a speed and current PI controller to meet the motor speed regulation requirements. The detailed control method is shown in Figure 6. When the motor is running during the commutation period, $T_{c}$ is turned on. The voltage scalar $V_{\mathrm{m} 2}$ is selected as the inverter input voltage, and the non-commutation current stabilization strategy is adopted to adjust the power switch $\mathrm{T}_{7}$ in the SIDO Cuk converter in order to meet the voltage demand during the commutation period. The inverter is only controlled by PAM mode, and it only performs the role of electronic commutation.

\section{Experimental Results and Analysis}

In order to verify the validity of the theoretical analysis and the effectiveness of the proposed strategy, an experimental system, as shown in Figure 9, was established. 


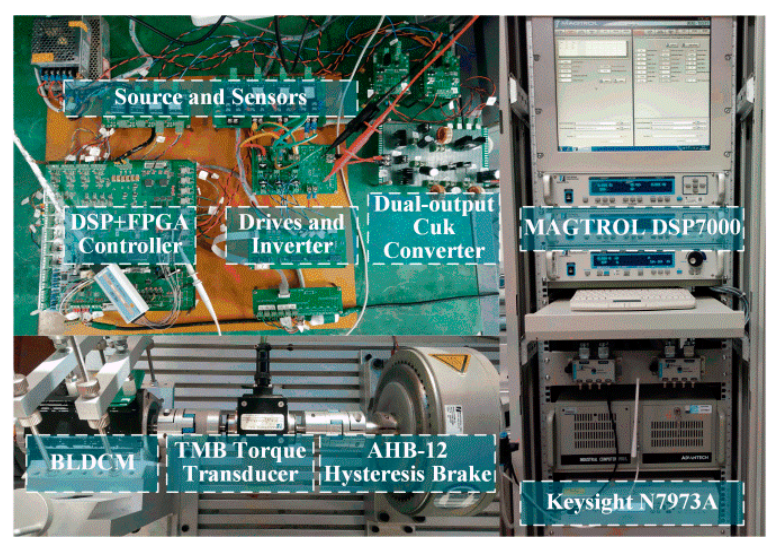

Figure 9. The experimental system.

The experimental system was built based on DSP and FPGA. The BLDCM phase current is measured by CSM025A. The basic parameters of the experimental motor are listed in Table 1. The parameters of the SIDO Cuk converter are selected by the method in [19]. The values of capacitors $C_{1}-C_{3}$ are $1000 \mu \mathrm{F}, 670 \mu \mathrm{F}$, and $1000 \mu \mathrm{F}$, respectively, and the values of inductors $L_{1}-L_{3}$ both use $330 \mu \mathrm{H}$. The DC voltage is provided by the Keysight N7973A DC power supply. The load is provided by the MAGTROL motor test system. The experimental results are recorded by a Yokogawa DLM4058 digital oscilloscope, and the inverter switching signals and SIDO Cuk converter drive signals $T_{7}$ and $T_{8}$ are obtained through the logic probe PBL100.

Table 1. The parameters of the motor.

\begin{tabular}{ccc}
\hline Parameter & Value & Unit \\
\hline Rated voltage $U_{\mathrm{N}}$ & 24 & $\mathrm{~V}$ \\
Rated current $I_{\mathrm{N}}$ & 14 & $\mathrm{~A}$ \\
Rated torque $T_{\mathrm{N}}$ & 3.2 & $\mathrm{~N} \cdot \mathrm{m}$ \\
Rated speed $n_{\mathrm{N}}$ & 600 & $\mathrm{r} / \mathrm{min}$ \\
Phase resistance $R$ & 0.2415 & $\Omega$ \\
Phase inductance $L$ & 0.387 & $\mathrm{mH}$ \\
Phase Back EMF coefficient $K_{\mathrm{e}}$ & 0.128 & $\mathrm{~V} /(\mathrm{rad} / \mathrm{s})$ \\
Poles pairs $p$ & 4 & \\
\hline
\end{tabular}

According to section 3.43 of IEC 60034-20-1, the torque ripple rate $K_{\mathrm{rT}}$ is defined as

$$
K_{\mathrm{rT}}=\frac{T_{\text {high }}-T_{\text {low }}}{T_{\text {high }}+T_{\text {low }}} \times 100 \%
$$

where, $T_{\text {high }}$ and $T_{\text {low }}$ are the maximum and minimum torque values in a given period of time.

The comparison is made based on the ON-PWM modulation strategy of the double closed loop of the speed and current. In the experiment, the DC power supply voltages of the traditional and proposed strategies are set to $24 \mathrm{~V}$ and $22 \mathrm{~V}$, respectively. Experiments are carried out under rated condition $\left(n^{*}=600 \mathrm{r} / \mathrm{min}, T_{\mathrm{L}}=3.2 \mathrm{~N} \cdot \mathrm{m}\right)$. The experimental results of the two strategies are shown in Figure 10a,b. 


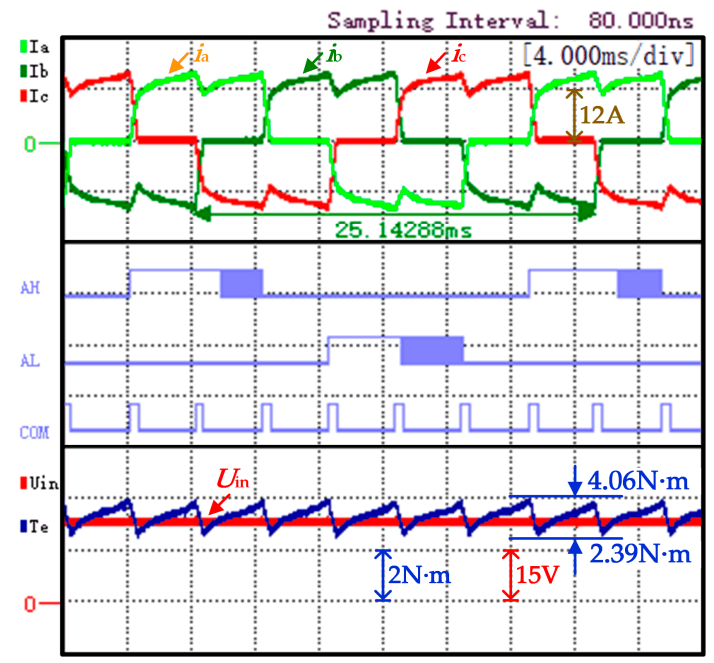

(a)

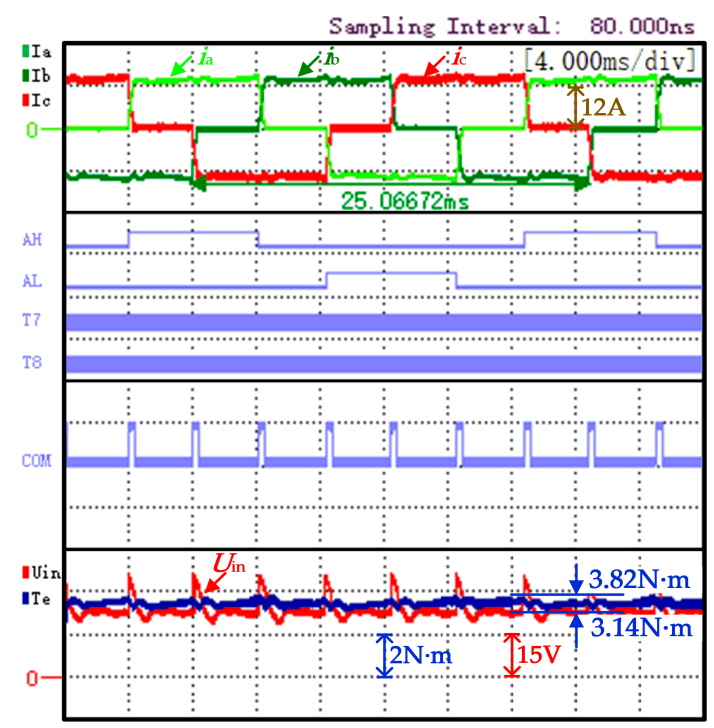

(b)

Figure 10. The experimental results with rated condition: (a) traditional strategy; and (b) proposed strategy.

The traditional strategy experiment waveform, shown in Figure 10a, is represented from top to bottom as three phase currents $\left(i_{\mathrm{A}}, i_{\mathrm{B}}\right.$, and $\left.i_{\mathrm{C}}\right)$, A-phase PWM signal ( $\mathrm{AH}$ is the upper arm, $\mathrm{AL}$ is the bridge arm), the commutation signal "COM", the input voltage of the inverter $\left(U_{\text {in }}\right)$, and electromagnetic torque $\left(T_{\mathrm{e}}\right)$. The power supply voltage satisfies $U_{\mathrm{dc}}=u_{\mathrm{N}}=24 \mathrm{~V}$; it can be observed that the non-commutated phase current has obvious ripples with $K_{\mathrm{rT}}$ being $25.4 \%$. The proposed strategy experiment waveform is shown in Figure 10b. At this time, the power supply voltage $U_{\mathrm{dc}}=22 \mathrm{~V}$; it can be observed that the torque ripple is significantly reduced with $K_{\mathrm{rT}}$ being $9.8 \%$.

Figure 11a,b are enlarged views of Figure 10a,b, respectively, during the B $+\mathrm{A}-\rightarrow \mathrm{C}+\mathrm{A}-$ commutation period, and the waveform definition is the same as that of Figure 10. 


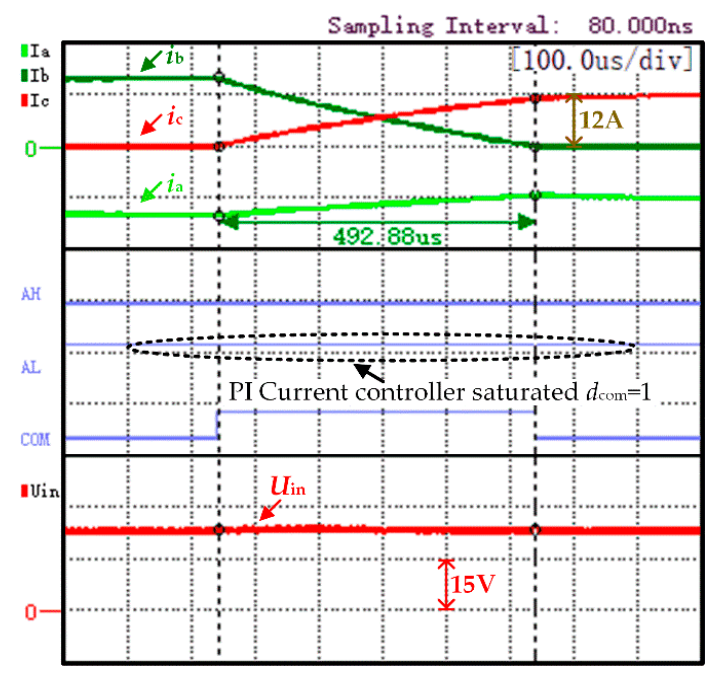

(a)

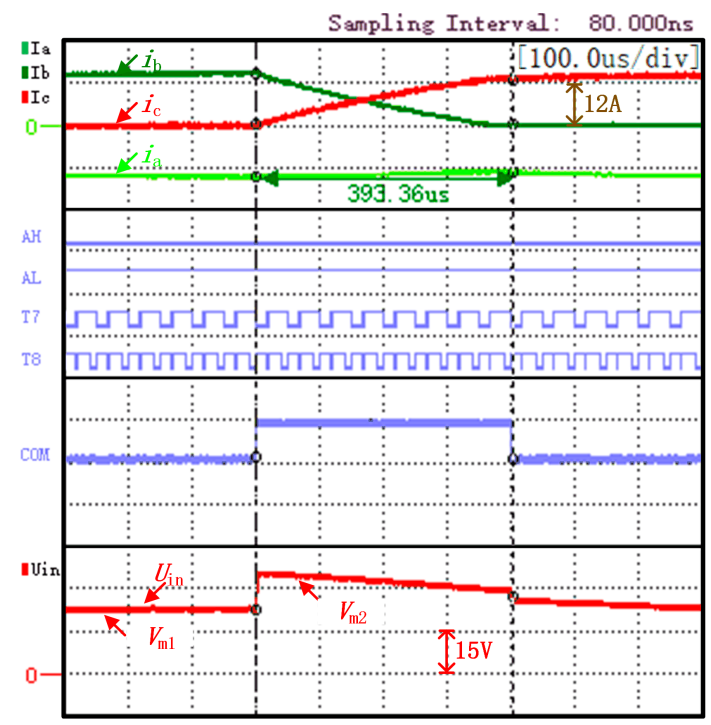

(b)

Figure 11. The enlarged views of the experimental results with rated condition: (a) traditional strategy; and (b) proposed strategy.

From the commutation period of the traditional strategy shown in Figure 11a, it can be observed that the power supply voltage of the system is constant, and the output of the current PI controller is saturated. At this time, $d_{\mathrm{com}}=1$, and the non-commutation phase current cannot be kept stable. Under the proposed strategy shown in Figure 11b, the inverter input voltage has two different values during the non-commutation period and the commutation period. During the non-commutation period, the voltage scalar $V_{\mathrm{m} 1}$ is selected to meet the motor speed regulation requirements. During the commutation period, the voltage scalar $V_{\mathrm{m} 2}$ is selected to meet the voltage required to keep the non-commutation current stable.

Experiments are carried out under light load conditions $\left(n^{*}=600 \mathrm{r} / \mathrm{min}, T_{\mathrm{L}}=1.6 \mathrm{~N} \cdot \mathrm{m}\right)$. The experimental results of the two strategies are shown in Figure 12a,b. The waveform definition of Figure 12 is the same as that of Figure 10. The torque ripple rate of the traditional strategy, with $K_{\mathrm{rT}}$ being $19.6 \%$, can be observed in Figure 12a, and the torque ripple rate of the proposed strategy, with $K_{\mathrm{rT}}$ being $14.4 \%$, can be observed in Figure $12 \mathrm{~b}$. 


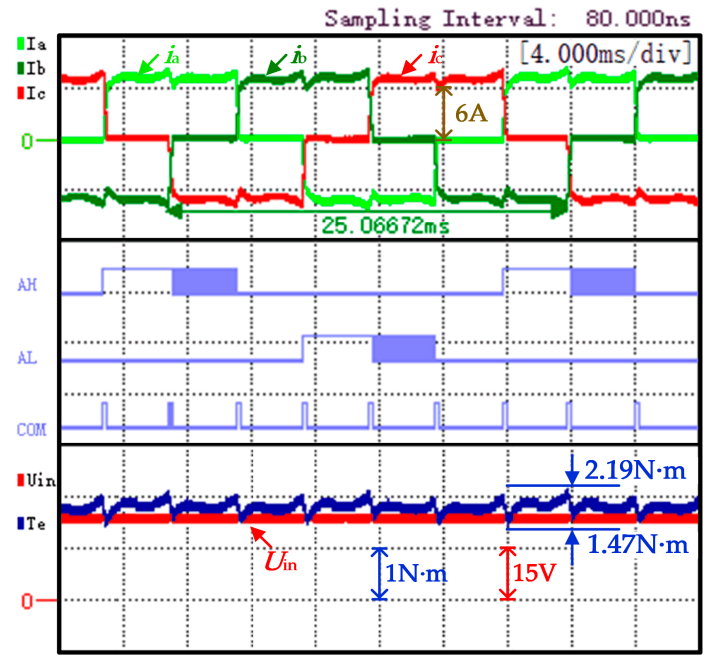

(a)

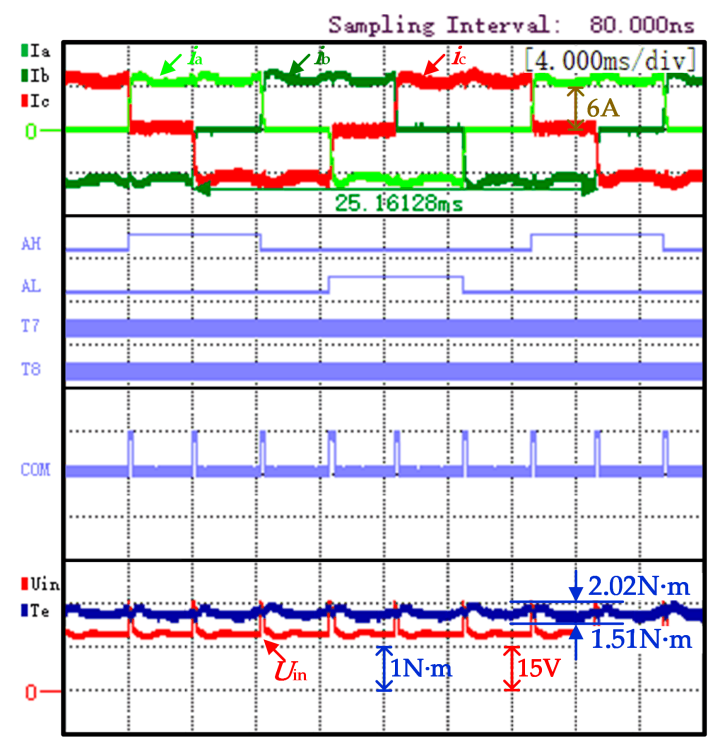

(b)

Figure 12. The experimental results with light load condition: (a) traditional strategy; and (b) proposed strategy.

Experiments are carried out under low speed conditions $\left(n^{*}=200 \mathrm{r} / \mathrm{min}, T_{\mathrm{L}}=3.2 \mathrm{~N} \cdot \mathrm{m}\right)$. The experimental results of the two strategies are shown in Figure 13a,b. The waveform definition of Figure 13 is the same as that of Figure 10. From Figure 13a,b, it can be observed that the torque ripple $K_{\mathrm{rT}}$ of the traditional strategy and the proposed strategy are $11.2 \%$ and $11.0 \%$, respectively. The non-commutated current can be effectively kept stable by the two strategies under low speed condition. Through the above analysis, the commutation torque ripple is effectively suppressed by the proposed strategy, and the inverter is only controlled by the PAM method, which can make the motor phase current smoother. 


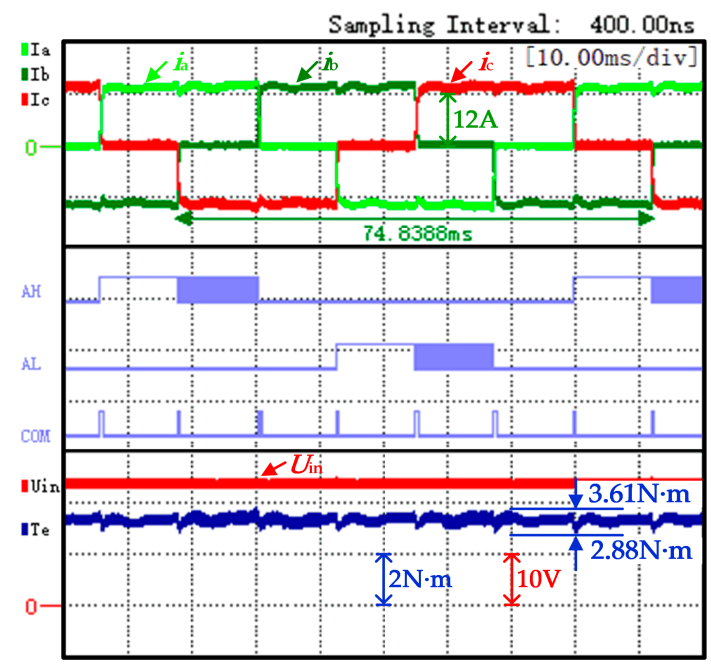

(a)

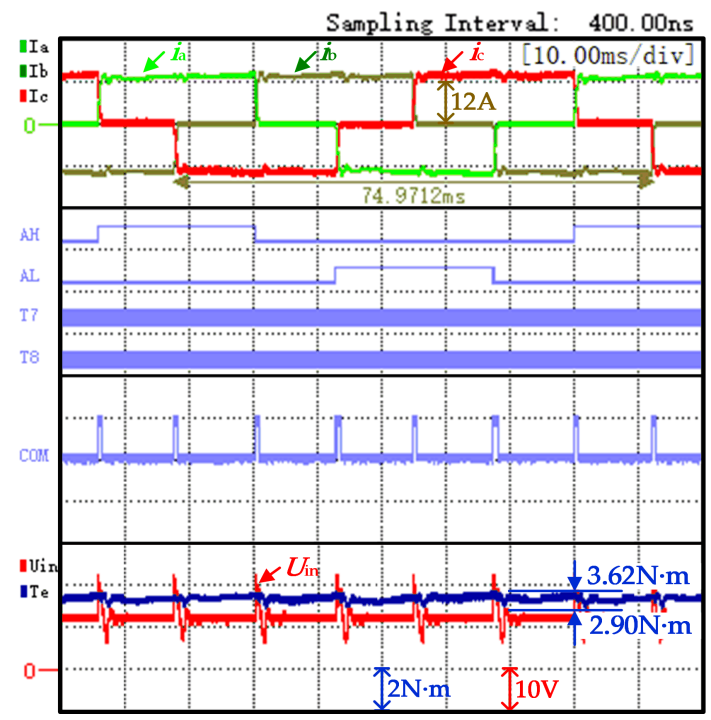

(b)

Figure 13. The experimental results with low speed condition: (a) traditional strategy; and (b) proposed strategy.

In order to provide more clarity on the feasibility and effectiveness of the method proposed in this paper, used to suppress the commutation torque ripple, the commutation torque ripple rates in the experiments under different working conditions are summarized, as shown in Table 2.

Table 2. Torque ripple rate $K_{\mathrm{rT}}$ under different operating conditions.

\begin{tabular}{cccc}
\hline Working Conditions & $\begin{array}{c}\text { Rated } \\
\text { Condition }\end{array}$ & $\begin{array}{c}\text { Light Load } \\
\text { Condition }\end{array}$ & $\begin{array}{c}\text { Low Speed } \\
\text { Condition }\end{array}$ \\
Control Strategies & $25.4 \%$ & $19.6 \%$ & $11.2 \%$ \\
Traditional strategy & $9.8 \%$ & $14.4 \%$ & $11.0 \%$ \\
Proposed strategy & & & \\
\hline
\end{tabular}

It can be observed from Table 2 that, under the rated operating condition, the $K_{\mathrm{rT}}$ of the proposed strategy is reduced by $15.6 \%$ compared with the traditional strategy. Under light load condition, the $K_{\mathrm{rT}}$ of the proposed strategy is reduced by $5.2 \%$ compared with 
the traditional strategy. Under low speed condition, both the proposed strategy and the traditional strategy can effectively reduce the commutation torque ripple. In summary, the commutation torque ripple can be effectively suppressed by the proposed strategy in this paper.

In order to verify the effectiveness of the proposed strategy in dynamic response, information is provided herein. The experimental result of the speed dynamic response with a reference torque of $3.2 \mathrm{~N} \cdot \mathrm{m}$ is shown in Figure 14. Figure 14a displays the experimental result of the speed ramping from $200 \mathrm{r} / \mathrm{min}$ to $600 \mathrm{r} / \mathrm{min}$. The partial enlarged view of dynamic response is shown in Figure 14b. Each waveform, from top to bottom, is the motor speed $\left(n^{*}, n\right)$, the three phase currents $\left(i_{\mathrm{A}}, i_{\mathrm{B}}\right.$ and $\left.i_{\mathrm{C}}\right)$, and the input voltage of the inverter $\left(U_{\mathrm{in}}\right)$. In Figure $14 \mathrm{a}$, during the acceleration process, the voltage scalars $V_{\mathrm{m} 1}$ and $V_{\mathrm{m} 2}$ increase with the increase of the motor speed. In Figure 14b, it can be observed that the non-commutated current can be stabilized by the proposed strategy during the speed change process.

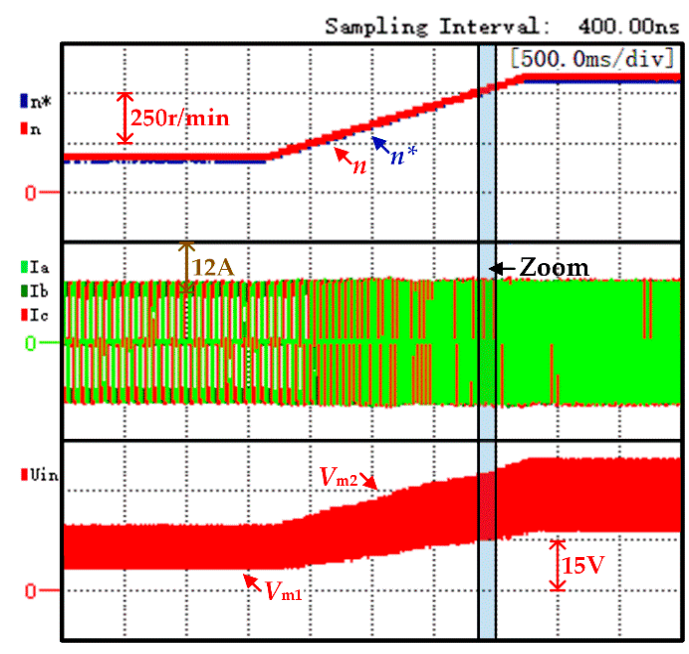

(a)

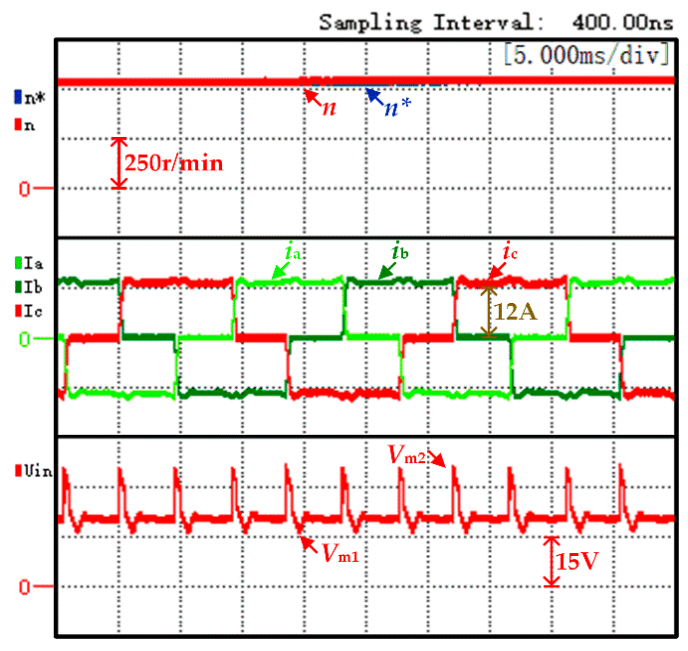

(b)

Figure 14. Dynamic response of speed variation in the proposed strategy $\left(T_{L}=3.2 \mathrm{~N} \cdot \mathrm{m}\right)$ : $(\mathbf{a})$ overall view; and (b) enlarged view.

\section{Conclusions}

A commutation torque ripple suppression strategy based on the SIDO Cuk converter is proposed in this paper. The proposed strategy has the following advantages:

1. Compared with the traditional strategy, the SIDO Cuk converter can be extended to the application of a low-voltage DC power supply, and the power supply voltage utilization rate can be improved.

2. The different voltage scalars constructed by the proposed strategy are selected during the non-commutation period and the commutation period, respectively, and the commutation torque ripple in the full speed range is effectively reduced; this occurs without the need to switch the control strategy according to the speed.

3. The inverter is only controlled by the PAM method, which minimizes the voltage spike damage caused by the power switch chopping to the motor.

Author Contributions: Conceptualization, X.L. and W.C.; Data curation, X.J.; Formal analysis, W.C.; Funding acquisition, X.L. and L.Y.; Investigation, X.J.; Methodology, X.L. and J.D.; Project administration, L.Y.; Resources, L.Y.; Software, J.D.; Supervision, W.C.; Validation, J.D.; Writing-original draft, J.D. All authors have read and agreed to the published version of the manuscript.

Funding: This research was funded by "The Fundamental Research Funds for the Central Universities from the Civil Aviation University of China, grant number 3122020024". 
Institutional Review Board Statement: Not applicable.

Informed Consent Statement: Not applicable.

Data Availability Statement: Not applicable.

Conflicts of Interest: The authors declare no conflict of interest.

\section{References}

1. Chen, X.; Liu, G. Sensorless Optimal Commutation Steady Speed Control Method for a Nonideal Back-EMF BLDC Motor Drive System Including Buck Converter. IEEE Trans. Ind. Electron. 2020, 67, 6147-6157. [CrossRef]

2. Xu, X.; Deng, Y. UAV Power Component-DC Brushless Motor Design with Merging Adjacent-Disturbances and IntegratedDispatching Pigeon-Inspired Optimization. IEEE Trans. Magn. 2018, 54, 1-7. [CrossRef]

3. Chau, K.T.; Chan, C.C.; Liu, C. Overview of Permanent-Magnet Brushless Drives for Electric and Hybrid Electric Vehicles. IEEE Trans. Ind. Electron. 2008, 55, 2246-2257. [CrossRef]

4. Dunkl, S.; Muetze, A.; Schoener, G. Design Constraints of Small Single-Phase Permanent Magnet Brushless DC Drives for Fan Applications. IEEE Trans. Ind. Appl. 2015, 51, 3178-3186. [CrossRef]

5. Carev, V.; Roháè, J.; Šipoš, M.; Schmirler, M. A Multilayer Brushless DC Motor for Heavy Lift Drones. Energies 2021, 14, 2504. [CrossRef]

6. Chen, S.; Liu, G.; Zhu, L. Sensorless Startup Strategy for a 315-kW High-Speed Brushless DC Motor with Small Inductance and Nonideal Back EMF. IEEE Trans. Ind. Electron. 2019, 66, 1703-1714. [CrossRef]

7. Fang, J.; Li, H.; Han, B. Torque Ripple Reduction in BLDC Torque Motor with Nonideal Back EMF. IEEE Trans. Power Electron. 2012, 27, 4630-4637. [CrossRef]

8. Sikora, A.; Woźniak, M. Impact of Current Pulsation on BLDC Motor Parameters. Sensors 2021, 21, 587. [CrossRef] [PubMed]

9. Carlson, R.; Lajoie-Mazenc, M. Analysis of torque ripple due to phase commutation in brushless DC machines. IEEE Trans. Ind. Appl. 1992, 28, 632-638. [CrossRef]

10. Shi, J.; Li, T. New Method to Eliminate Commutation Torque Ripple of Brushless DC Motor with Minimum Commutation Time IEEE Trans. Ind. Electron. 2013, 60, 2139-2146. [CrossRef]

11. Xia, C.; Xiao, Y.; Chen, W.; Shi, T. Torque Ripple Reduction in Brushless DC Drives Based on Reference Current Optimization Using Integral Variable Structure Control. IEEE Trans. Ind. Electron. 2014, 61, 738-752. [CrossRef]

12. Park, J.; Lee, D. Simple Commutation Torque Ripple Reduction Using PWM with Compensation Voltage. IEEE Trans. Ind. Appl. 2020, 56, 2654-2662. [CrossRef]

13. Changliang, X.; Yingfa, W.; Tingna, S. Implementation of Finite-State Model Predictive Control for Commutation Torque Ripple Minimization of Permanent-Magnet Brushless DC Motor. IEEE Trans. Ind. Electron. 2013, 60, 896-905.

14. Shi, T.; Cao, Y.; Jiang, G.; Li, X.; Xia, C. A Torque Control Strategy for Torque Ripple Reduction of Brushless DC Motor with Nonideal Back Electromotive Force. IEEE Trans. Ind. Electron. 2017, 64, 4423-4433. [CrossRef]

15. Kim, D.; Lee, K.; Kwon, B. Commutation Torque Ripple Reduction in a Position Sensorless Brushless DC Motor Drive. IEEE Trans. Power Electron. 2006, 21, 1762-1768. [CrossRef]

16. Shi, T.; Guo, Y.; Song, P.; Xia, C. A New Approach of Minimizing Commutation Torque Ripple for Brushless DC Motor Based on DC-DC Converter. IEEE Trans. Ind. Electron. 2010, 57, 3483-3490. [CrossRef]

17. Li, X.; Xia, C.; Cao, Y.; Chen, W.; Shi, T. Commutation Torque Ripple Reduction Strategy of Z-Source Inverter Fed Brushless DC Motor. IEEE Trans. Power Electron. 2016, 31, 7677-7690. [CrossRef]

18. Chen, W.; Liu, Y.; Li, X.; Shi, T.; Xia, C. A Novel Method of Reducing Commutation Torque Ripple for Brushless DC Motor Based on Cuk Converter. IEEE Trans. Power Electron. 2017, 32, 5497-5508. [CrossRef]

19. Chen, G.; Jin, Z.; Deng, Y.; He, X.; Qing, X. Principle and Topology Synthesis of Integrated Single-Input Dual-Output and Dual-Input Single-Output DC-DC Converters. IEEE Trans. Ind. Electron. 2018, 65, 3815-3825. [CrossRef] 